\title{
Selection of reference genes for quantitative real-time PCR in equine in vivo and fresh and frozen-thawed in vitro blastocysts Katrien Smits ${ }^{1}$, Karen Goossens*2, Ann Van Soom¹, Jan Govaere ${ }^{1}$, Maarten Hoogewijs ${ }^{1}$, Emilie Vanhaesebrouck ${ }^{1}$, Cesare Galli3,5, Silvia Colleoni ${ }^{3}$, Jo Vandesompele ${ }^{4}$ and Luc Peelman ${ }^{2}$
}

Address: ${ }^{1}$ Department of Reproduction, Obstetrics and Herd Health, Faculty of Veterinary Medicine, Ghent University, Salisburylaan 133 , B-9820 Merelbeke, Belgium, 2Department of Nutrition, Genetics and Ethology, Faculty of Veterinary Medicine, Ghent University, Heidestraat 19, 9820 Merelbeke, Belgium, ${ }^{3}$ Laboratorio di Tecnologie della Riproduzione, AVANTEA srl, Cremona, Italy, ${ }^{4}$ Center for Medical Genetics, Ghent University Hospital, De Pintelaan 185, 9000 Gent, Belgium and ${ }^{5}$ Dipartimento Clinico Veterinario, Università di Bologna, Italy

Email: Katrien Smits - katrien.smits@ugent.be; Karen Goossens* - karen.goossens@ugent.be; Ann Van Soom - ann.vansoom@ugent.be; Jan Govaere - jan.govaere@ugent.be; Maarten Hoogewijs - maarten.hoogewijs@ugent.be; Emilie Vanhaesebrouck - emilie.vanhaesebrouck@ugent.be; Cesare Galli - cesaregalli@avantea.it; Silvia Colleoni - silviacolleoni@avantea.it; Jo Vandesompele - Joke.Vandesompele@ugent.be; Luc Peelman - luc.peelman@ugent.be

* Corresponding author

Published: II December 2009

BMC Research Notes 2009, 2:246

This article is available from: http://www.biomedcentral.com//756-0500/2/246

(c) 2009 Goossens et al; licensee BioMed Central Ltd.

This is an Open Access article distributed under the terms of the Creative Commons Attribution License (http://creativecommons.org/licenses/by/2.0), which permits unrestricted use, distribution, and reproduction in any medium, provided the original work is properly cited.
Received: 21 October 2009

Accepted: II December 2009

\begin{abstract}
Background: Application of reverse transcription quantitative real-time polymerase chain reaction is very well suited to reveal differences in gene expression between in vivo and in vitro produced embryos. Ultimately, this may lead to optimized equine assisted reproductive techniques. However, for a correct interpretation of the real-time PCR results, all data must be normalized, which is most reliably achieved by calculating the geometric mean of the most stable reference genes. In this study a set of reliable reference genes was identified for equine in vivo and fresh and frozen-thawed in vitro embryos.

Findings: The expression stability of 8 candidate reference genes (ACTB, GAPDH, H2A/l, HPRTI, RPL32, SDHA, TUBA4A, UBC) was determined in 3 populations of equine blastocysts (fresh in vivo, fresh and frozen-thawed in vitro embryos). Application of geNorm indicated UBC, GAPDH, ACTB and HPRTI as the most stable genes in the in vivo embryos and UBC, RPL32, GAPDH and ACTB in both in vitro populations. When in vivo and in vitro embryos were combined, UBC, ACTB, RPL32 and GAPDH were found to be the most stable. SDHA and H2A/l appeared to be highly regulated.
\end{abstract}

Conclusions: Based on these results, the geometric mean of UBC, ACTB, RPL32 and GAPDH is to be recommended for accurate normalization of quantitative real-time PCR data in equine in vivo and in vitro produced blastocysts.

\section{Background}

Conventional IVF has been rather unsuccessful in horses. To overcome this barrier ICSI has been introduced and has resulted in transferable blastocysts that were used for research and commercial purposes [1-3]. The ability of in vitro produced blastocysts to establish normal pregnancies is comparable to that of the in vivo derived ones and, contrary to other species, in vitro produced equine blastocysts 
tolerate freezing better than in vivo produced ones and they are able to establish pregnancies after thawing [1]. Despite these successes, there is a great variability in oocyte quality and culture conditions resulting in a low percentage of blastocyst formation in vitro with great variations amongst laboratories. Compared to their in vivo counterparts, in vitro blastocysts are retarded in the kinetics of development, are smaller with fewer cells, show more apoptosis and higher levels of chromosomal abnormalities [4-6]. Moreover intra-uterine transfer of in vitro produced embryos can give rise to abnormal pregnancies with the development of a trophoblastic vesicle without an embryo proper [2]. Understanding the fundamental difference between equine in vivo versus in vitro embryos may prove beneficial in the development of equine assisted reproductive techniques.

RT-qPCR is a highly specific and sensitive tool to compare mRNA expression levels of specific genes [7]. Not only the RNA quality, the RT, the reagents and the protocol are critical factors, the analytical method can also influence the results dramatically $[7,8]$. All data must be normalized for technical differences between samples. The method of preference consists in normalization to internal reference genes, which should be constitutively expressed without influence of the experimental treatment. Since there is no universal reference gene with a constant expression in all tissues, optimal reference genes need to be selected for each system [9]. The use of a single reference gene or of multiple unstable reference genes may lead to erroneous normalization [10]. Therefore the geometric mean of carefully selected genes is recommended for reliable normalization [11].

Reference genes have been validated in preimplantation embryos of cattle [12], mice [13], pigs [14] and rabbits [15]. However gene stability in mammalian embryos turned out to be species specific, which implies the need of reference gene selection for the study of equine embryos. Gene expression studies in equine species are relatively scarce. Real-time PCR has been conducted on equine conceptuses to evaluate expression of progesterone and oestrogen receptors and on equine blastocysts to identify POU5F1 expression, but in these studies only one reference gene, $\beta$-actin, was used $[16,17]$. While sets of reference genes have been identified for equine skin [18] and lymphocytes [19], the most reliable reference genes in equine embryos have not been studied before.

The aim of this study was to identify a set of stable reference genes for equine in vivo derived embryos and fresh and frozen-thawed in vitro embryos.

\section{Methods}

The in vivo blastocyst collection procedures used were approved by the ethics committee of the faculty of veteri- nary medicine (reference number EC 2007/009). Cycling mares were followed up by transrectal ultrasound. When the follicle size exceeded $35 \mathrm{~mm}$ in the presence of an edematous uterus, 3000 IU hCG (Chorulon, Intervet, Belgium) was injected intravenously. The next day the mare was inseminated with fresh semen. Ultrasound was performed daily until ovulation was detected. If the mare did not ovulate within 48 hours after AI, insemination was repeated. The mares' uterus was flushed 7 days after ovulation and recovered embryos were washed in DPBS (14190, Gibco, Invitrogen, Belgium) and conserved individually at $-80^{\circ} \mathrm{C}$ in lysis buffer $(10 \%$ RNasin Plus RNase inhibitor (Promega, The Netherlands), 5\% dithiothreitol (Promega, The Netherlands), 0.8\% Igepal CA-630 (Sigma, Belgium) in RNase free water until further analysis.

For the production of fresh in vitro blastocysts, ovaries were recovered from slaughtered mares and follicles $\geq 5$ $\mathrm{mm}$ were aspirated with a vacuum pump at a negative pressure of $100 \mathrm{~mm} \mathrm{Hg}$. The follicle wall was scraped with the aspirating 16 gauge needle and flushed with $0.5 \%(\mathrm{v} /$ v) heparin (H 1027, Sigma, Belgium) in DPBS (14190, Gibco, Invitrogen, Belgium). Oocytes were matured for 28 $\mathrm{h}$ in DMEM-F12 based medium [1] at $38.5^{\circ} \mathrm{C}$ in $5 \% \mathrm{CO}_{2}$ in air. The MII oocytes were fertilized by conventional ICSI as described by Tremoleda et al. [20]. Frozen-thawed sperm was used from the same stallion that was used for production of in vivo embryos. In vitro culture was performed for 8.5 to 9.5 days in DMEM-F12 (D 2906, Sigma, Belgium) with 10\% FCS (F 9665, Sigma, Belgium) or 5\% FCS and 5\% SR (10828-028, Gibco, Invitrogen, Belgium) at $38.5^{\circ} \mathrm{C}$ in $5 \% \mathrm{CO}_{2}, 5 \% \mathrm{O}_{2}$ and $90 \% \mathrm{~N}_{2}$. Blastocysts were stored individually at $-80^{\circ} \mathrm{C}$ in lysis buffer until further analysis.

The frozen-thawed in vitro embryos were produced in Italy. Briefly, oocytes were recovered from abbatoir ovaries by scraping and washing all the follicles between 5 and $30 \mathrm{~mm}$. Oocytes were washed in HEPES buffered TCM199 and transferred for $24 \mathrm{~h}$ into DMEM-F12 based maturation medium as previously described [1]. After removal of all cumulus cells, the oocytes with a polar body were fertilized by ICSI with frozen-thawed sperm from stallions of proven fertility. Injected oocytes were cultured up to day 8 in $20 \mu \mathrm{l}$ drops of modified SOF (from day 6 half SOF: half DMEM-F12) at $38.5^{\circ} \mathrm{C}$ in $5 \% \mathrm{CO}_{2}$, $5 \% \mathrm{O}_{2}$ and $90 \% \mathrm{~N}_{2}$. Embryos that reached the blastocyst stage were loaded individually into $0.25 \mathrm{ml}$ straws, frozen with a slow cooling protocol $\left(0.5^{\circ} \mathrm{C} / \mathrm{min}\right.$ up to $\left.-32^{\circ} \mathrm{C}\right)$ in glycerol and stored in liquid $\mathrm{N}_{2}$. The embryos were shipped to Belgium in dry ice and upon arrival they were immediately transferred into lysis buffer with a minimum of medium and conserved at $-80^{\circ} \mathrm{C}$ until further analysis.

In all groups only blastocysts which were not hatched and had good morphological characteristics were retained. 
For each of the 3 groups 8 embryos were analysed separately. Total RNA was extracted from single embryos with the PicoPure RNA-isolation Kit (Arcturus, USA), treated with RQ1 DNAse (Promega, The Netherlands) and purified over a spin column (Microcon YM-100, Millipore, Belgium). After minus RT control with primers for GAPDH to check for contaminating genomic DNA, RNA was concentrated by precipitation with $3 \mathrm{M}$ sodium acetate and ethanol. RNA amplification and conversion into cDNA was performed by means of the WT-Ovation RNA Amplification System (NuGEN, USA) according to the manufacturers' instructions and the cDNA was purified again over a spin column. Amplified cDNA samples were diluted 10-20 times, depending on the yield, in $10 \mathrm{mM}$ Tris HCL pH 8.0 and stored at $-80^{\circ} \mathrm{C}$.

Eight reference genes were selected based on previous studies $[12,18,19]$. The selected genes (ACTB, GAPDH, H2A/I, HPRT, RPL32, SDHA, TUBA4A and UBC) belong to different functional classes, which reduces the chance of co-regulation.

Primers for ACTB, HPRT1, RPL32, TUBA4A and UBC were provided by Bogaert and colleagues [18]. The other primers were designed by means of Primer3 software http:// frodo.wi.mit.edu/primer3/, based on horse sequences found in the NCBI GenBank http:// www.ncbi.nlm.nih.gov/. Primers were selected over intron-exon boundaries, tested using a BLAST analysis against the NCBI database and verified using MFold http:/ frontend.bioinfo.rpi.edu/applications/mfold/cgi-bin/ dna-form1.cgi. The optimal primer annealing temperatures were determined on cDNA of equine mixed tissues. A melt curve analysis followed by agarose gel electro- phoresis was performed to test for primer-dimer formation and specificity of the amplicons. All primers are listed in Table 1.

All reactions were executed in duplicate for 8 embryos in each of the three groups and a blank was included in each run.

The diluted cDNA $(2.5 \mu \mathrm{l}), 0.33 \mu \mathrm{M}$ of both forward and reverse primers and $4 \mu \mathrm{l}$ of RNAse free water were added to $7.5 \mu \mathrm{l}$ of KAPA SYBR FAST qPCR Master Mix (KAPA Biosystems) to a final volume of $15 \mu \mathrm{l}$. The reactions were performed on the iCycler iQ Real-Time PCR Detection System (Bio-Rad, Belgium).

The PCR program started with an initial denaturation at $95^{\circ} \mathrm{C}$ for 3 minutes to activate the DNA polymerase. Then 45 cycles were performed with a denaturation step at $95^{\circ} \mathrm{C}$ for 20 seconds followed by an annealing/extension step at the primer specific annealing temperature for 40 seconds during which fluorescence was measured. A dilution series with pooled cDNA from all 24 embryos was included for each gene to acquire PCR efficiencies based on a relative standard curve. Calculation of the $\mathrm{C}_{\mathrm{q}}$ values, PCR efficiencies, correlation coefficients and analysis of the melting curves was performed by means of iCycler iQ Optical System Software Version 3.0a. The standard errors of the PCR efficiencies were obtained by the qBasePlus software http://www.qbaseplus.com/.

The expression stabilities were evaluated using the geNorm software for Microsoft Excel [11]. This program ranks the genes based on the internal control gene stability parameter M. Stepwise exclusion of the gene with the

Table I: Primers

\begin{tabular}{|c|c|c|c|c|c|c|}
\hline Gene & $\begin{array}{l}\text { GenBank accession } \\
\text { number }\end{array}$ & Sequence & Amplicon size (bp) & $\mathrm{Ta}\left({ }^{\circ} \mathrm{C}\right)$ & RTprimerDB ID & $C_{q}$ range \\
\hline ACTB & AF035774 & $\begin{array}{l}\text { CCAGCACGATGAAGATCAAG } \\
\text { GTGGACAATGAGGCCAGAAT }\end{array}$ & 88 & 60 & 7848 & $16.3-23.8$ \\
\hline GAPDH & $\underline{X M \quad 001496020.1}$ & $\begin{array}{l}\text { CAGAACATCATCCCTGCTTC } \\
\text { ATGCCTGCTTCACCACСTTC }\end{array}$ & 187 & 59 & 7849 & | $4.2-24.5$ \\
\hline $\mathrm{H} 2 \mathrm{~A} / \mathrm{I}$ & XM 001497311.2 & $\begin{array}{l}\text { ATATTCAGGCCGTGCTGCT } \\
\text { TTTGGGTTTCAAAGCGTTTC }\end{array}$ & 105 & 60 & $*$ & $23.5-37.3$ \\
\hline HPRTI & AY372182 & $\begin{array}{l}\text { GGCAAAACAATGCAAACCTT } \\
\text { CAAGGGCATATCCTACGACAA }\end{array}$ & 163 & 57 & 7850 & $17.6-25.8$ \\
\hline RPL32 & $\underline{X M \quad 001492042.2}$ & $\begin{array}{l}\text { AGCCATCTACTCGGCGTCA } \\
\text { TCCAATGCCTCTGGGTTTC }\end{array}$ & 149 & 60 & $*$ & $16.8-25.9$ \\
\hline SDHA & $\underline{X M \quad 001490889}$ & $\begin{array}{l}\text { TCCATCGCATAAGAGCAAAG } \\
\text { GGTGGAACTGAACGAACTCC }\end{array}$ & 159 & 59 & 7851 & $20.7-33.3$ \\
\hline TUBA4A & XM 001491910.2 & $\begin{array}{l}\text { GCCCTACAACTCCATCCTGA } \\
\text { ATGGCTTCATTGTCCACCA }\end{array}$ & 78 & 60 & $*$ & $16.6-27.9$ \\
\hline UBC & AF506969 & $\begin{array}{l}\text { GCAAGACCATCACCCTGGA } \\
\text { CTAACAGCCACCCCTGAGAC }\end{array}$ & 206 & 60 & 7874 & 15.5-23.7 \\
\hline
\end{tabular}

For each reference gene, the NCBI GenBank accession number, the sequence of both forward and reverse primer, the size of the amplicon and the optimal primer annealing temperature are listed. The RTPrimerDB ID http://rtprimerdb.org/ is also reported, except for the primers for which there is not yet an official reference sequence available in the database $\left(^{*}\right)$. 
highest $M$ value and recalculation results in a ranking of the reference genes. Lower $M$ values represent higher expression stabilities. Furthermore the minimum number of genes required for the calculation of a reliable normalization factor is determined.

\section{Results and discussion}

For the recovery of the in vivo embryos $(\mathrm{n}=8) 13$ uterine flushes were performed in a population of 8 mares (recovery rate: $61.5 \%)$. To collect the fresh in vitro embryos $(\mathrm{n}=$ 8) 123 ovaries were recovered in 5 experiments which gave rise to a total number of 365 oocytes. Maturation was completed and ICSI was performed in 209 oocytes (57\%) and $74 \%$ of these injected oocytes cleaved. Of the cleaved oocytes $5.8 \%$ reached the blastocyst stage. The 8 in vitro blastocysts which were used for genetic analysis were produced in 2 of those 5 experiments where the blastocyst percentage was $7.3 \%$.

Frozen embryos were produced in experiments for quality control purposes. They were frozen on day 8 at the early blastocyst or blastocyst stage.

Prior to the start of the experiment, PCR was tested on one of the frozen-thawed embryos to evaluate possible effects of remnants of the cryoprotectant. Both undiluted and $25 \times$ diluted CDNA resulted in clear electrophoretic bands of expected size for $U B C$ and $A C T B$. Only a minimal amount of cryoprotectant accompanying the embryo was transferred to and diluted in the lysis buffer. Importantly $\mathrm{C}_{\mathrm{q}}$-values of the fresh and frozen-thawed embryos remained in the same range.

Because only a small quantity of RNA can be extracted from one embryo, an RNA pre-amplification step was included in the protocol. Ribo-SPIA, the isothermal messenger RNA amplification method used, has been shown to be accurate and reproducible [21]. High sensitivity permits quantification of low abundance transcripts and there is a good correlation in differential gene expression between amplified and nonamplified cDNA [21].

Dilution series of all candidate reference genes gave PCRefficiencies between $97.1 \%$ and $100 \%$ and linear correlation coefficients that varied from 0.973 to 1.000 . In table 2 the efficiencies and their standard errors are listed.

One in vivo and one fresh in vitro embryo consistently resulted in $\mathrm{C}_{\mathrm{q}}$-values around 40 . Probably the amplification went wrong and both samples were deleted from further analysis.

The selection of appropriate reference genes can be achieved by evaluating RT-qPCR data with statistical algorithms. The uniformity in gene ranking between geNorm
Table 2: PCR efficiency and the respectively standard error

\begin{tabular}{lcc}
\hline Gene & Efficiency (\%) & Standard error \\
\hline ACTB & 98.1 & 0.01 \\
GAPDH & 100 & 0.021 \\
H2A/I & 100 & 0.067 \\
HPRTI & 100 & 0.037 \\
RPL32 & 100 & 0.071 \\
SDHA & 99.3 & 0.033 \\
TUBA4A & 100 & 0.017 \\
UBC & 97.1 & 0.017 \\
\hline
\end{tabular}

[11], NormFinder [22] and BestKeeper [23] has been shown to be high $[19,24]$.

Results of the reference gene stability, as determined by geNorm, are shown in Figure 1, 2, 3 and 4. When all three groups of embryos were included, the most stable genes were $U B C, A C T B, R P L 32$ and GAPDH. The $\mathrm{M}$ values of these genes range between 0.6 and 0.9 , which indicates relatively good stability.

The order of the 4 most stable genes, UBC, RPL32, GAPDH and ACTB, is identical in both in vitro groups. This is an interesting finding as there was a difference in embryo culture conditions and as the cryopreservation could have affected the results. Three of those 4 genes, UBC, GAPDH and ACTB, represent the most stable genes in the in vivo embryos. In murine embryos the order of stability of reference genes has also been found to be similar in both in vitro and in vivo embryos [13]. In the latter study however, the stability measure values $M$ were described to be higher in the in vitro samples compared to

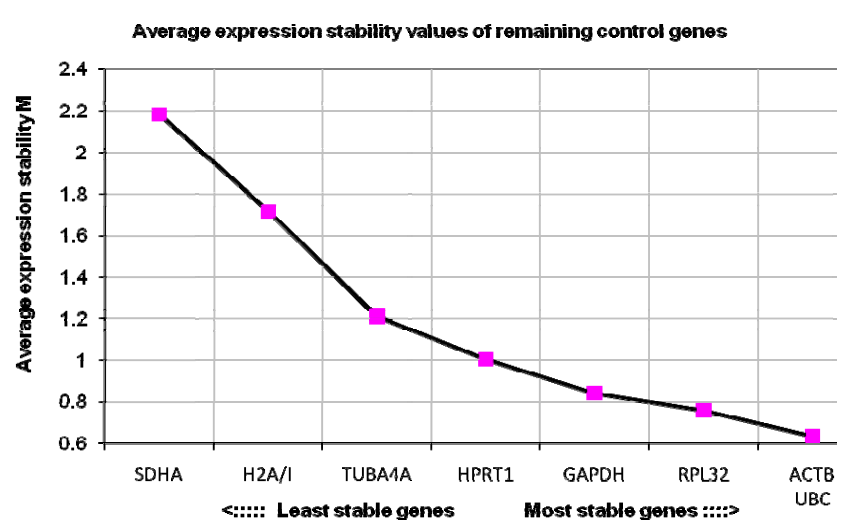

Figure I

Average expression stability values of equine in vivo and in vitro embryos. The average stability values of the control genes were calculated with geNorm. When in vivo embryos and fresh and frozen-thawed in vitro embryos were combined, UBC, ACTB, RPL32 and GAPDH were found to be the most stable. 


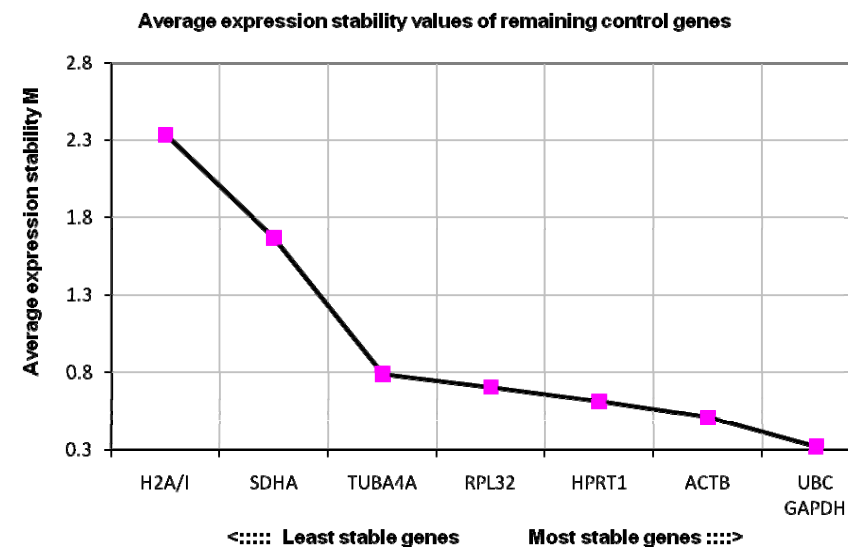

Figure 2

Average expression stability values of equine in vivo embryos. The average stability values of the control genes were calculated with geNorm. In the population of the equine in vivo embryos UBC, GAPDH, ACTB and HPRTI were found to be the most stable.

the in vivo samples, which was not the case in the equine embryos. SDHA and H2A/I generally turned out to be highly regulated.

These results differ from those in embryos from other species and from those in other equine tissues. SDHA, which was highly regulated in equine embryos, appeared to be very stable in bovine embryos [12] and equine lymphocytes [19]. This is also the case for $H 2 A / I$, which was preferred as a reference gene in embryos of mice [13] and rabbits [15]. ACTB on the other hand appears fairly stable

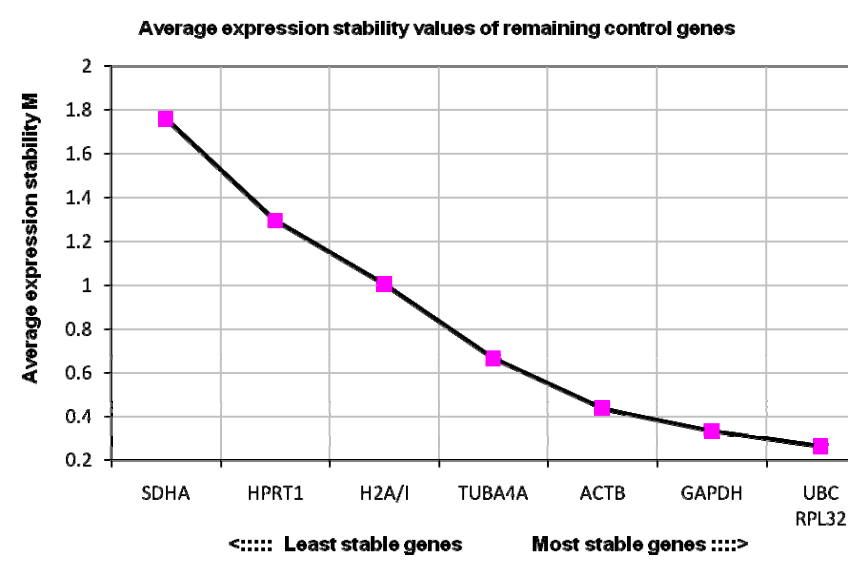

Figure 3

Average expression stability values of fresh equine in vitro embryos. The average stability values of the control genes were calculated with geNorm. In the population of the fresh equine in vivo embryos UBC, RPL32, GAPDH and ACTB were found to be the most stable.

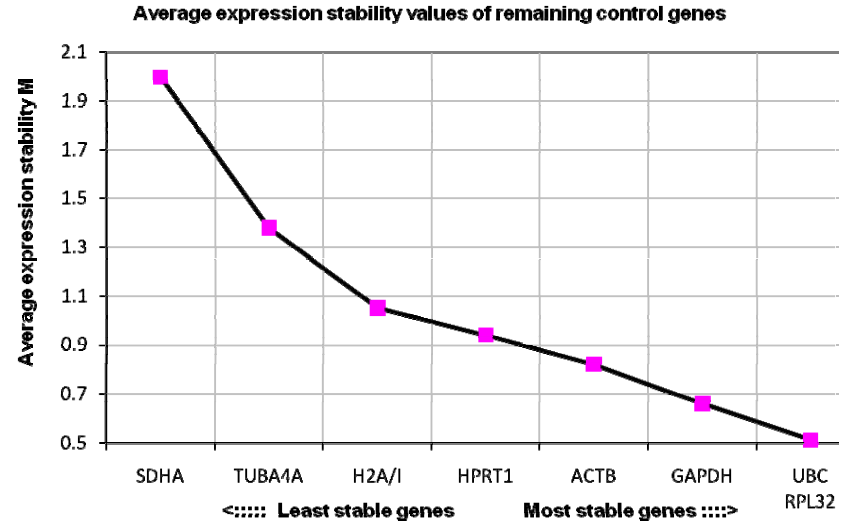

Figure 4

Average expression stability values of frozen-thawed equine in vitro embryos. The average stability values of the control genes were calculated with geNorm. In the population of the fresh equine in vivo embryos UBC, RPL32, GAPDH and ACTB were found to be the most stable.

in equine embryos, although it is highly regulated in bovine embryos [12]. This again demonstrates the necessity to validate the genes according to the species and the tissue type.

The use of the geometric mean of several internal control genes as a normalization factor (NF) is more accurate than the use of a single reference gene. Inclusion of unstable genes on the other hand negatively influences the NF and the number of reference genes used to calculate this NF is a trade-off between practical considerations and accuracy.

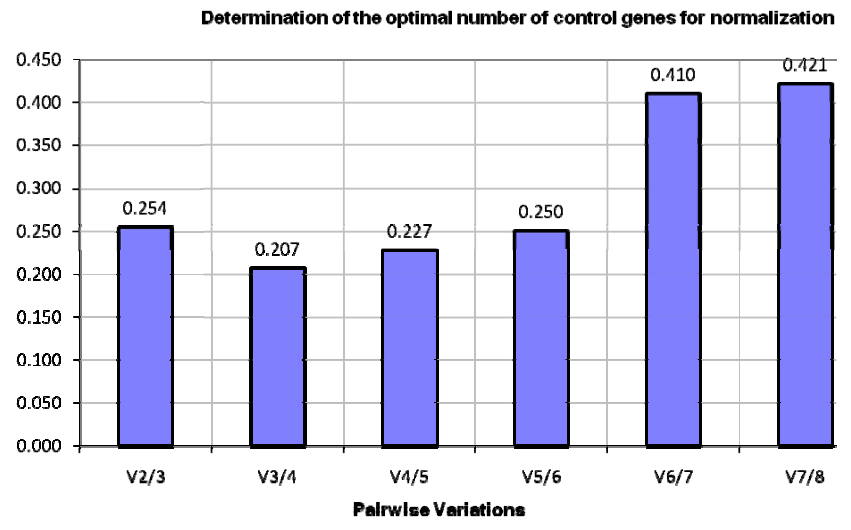

Figure 5

Determination of the optimal number of control genes for normalization. The optimal number of control genes for normalization was calculated by geNorm. The value of the pairwise variations reduces until 0.207 for $V_{3 / 4}$, which indicates that the inclusion a fourth reference gene contributes to the stability. Therefore the average of the 4 most stable genes is recommended to determine a reliable NF. 
The optimal number of genes was determined with geNorm by means of the pairwise variations $\left(\mathrm{V}_{\mathrm{n} / \mathrm{n}+1}\right)$ between the sequential normalization factors $\left(\mathrm{NF}_{\mathrm{n}}\right.$ and $\mathrm{NF}_{\mathrm{n}+1}$ ) after successive inclusion of less stable reference genes (Figure 5). The value of the pairwise variations reduces until 0.207 for $\mathrm{V}_{3 / 4}$. This suggests that the inclusion of a fourth reference gene contributes to the stability. Therefore it is recommended to use the 4 most stable genes, UBC, ACTB, RPL32 and GAPDH. The high values of $\mathrm{V}_{6 / 7}$ and $\mathrm{V}_{7 / 8}$ represent the instability of $H 2 \mathrm{~A} / \mathrm{I}$ and $S D H A$, which is also clear in the steep rise in Figure 1.

In conclusion, the geometric mean of $A C T B, U B C, R P L 32$ and GAPDH is recommended for normalization of RTqPCR data in experiments with equine in vivo and in vitro blastocysts.

\section{Abbreviations}

ACTB: beta actin; GAPDH: glyceraldehyde-3-phosphate dehydrogenase; H2A/I: histone H2A type 1-C; HPRT: hypoxanthine phosphoribosyltransferase 1; RPL32: ribosomal protein L32; SDHA: succinate dehydrogenase complex; subunit A; TUBA4A: tubulin; alpha 4a; UBC: ubiquitin C; IVF: in vitro fertilization; ICSI: intracytoplasmic sperm injection; RT-qPCR: reverse transcription quantitative real-time polymerase chain reaction; RT: reverse transcription; hCG: human chorionic gonadotropin. AI: artificial insemination; DPBS: Dulbecco's Phosphate Buffered Saline; DMEM-F12: Dulbecco's Modified Eagle Medium: Nutrient Mixture F-12; MII: metaphase II; FCS: fetal calf serum; SR: serum replacement; HEPES: 4(2-hydroxyethyl)-1-piperazineethanesulfonic acid; TCM199: Tissue Culture Medium199; SOF: synthetic oviduct fluid; MEM: Eagle's minimal essential medium; FAFBSA: fatty acid-free bovine serum albumin; $\mathrm{C}_{\mathrm{q}}$ value: quantification cycle value.

\section{Competing interests}

The authors declare that they have no competing interests.

\section{Authors' contributions}

KS performed all experiments and data analysis and was the primary author of the manuscript. KG provided support in all genetical procedures and in data analysis. JG, $\mathrm{MH}$ and $\mathrm{EVH}$ helped with the collection of the in vivo embryos. SC and CG provided the frozen-thawed in vitro embryos and helped with the optimization of the protocol for the fresh in vitro embryos. JV supported the data analysis. AVS and LP participated in the design of the project and supervised the study. All authors read and approved the final manuscript.

\section{Acknowledgements}

The authors like to thank L. Bogaert and C. De Baere for the provision of the primers and I. Lemahieu and P. Van Damme for their excellent technical assistance. This research was funded by the Special Research Fund, Ghent
University, grant no. 0ID04806. Work in Italy at Avantea was supported in part by the ESNATS project from the EU and from Regione Lombardia. The authors are members of the EU-COST Action FA0702-GEMINI for this section.

\section{References}

I. Galli C, Colleoni S, Duchi R, Lagutina I, Lazzari G: Developmental competence of equine oocytes and embryos obtained by in vitro procedures ranging from in vitro maturation and ICSI to embryo culture, cryopreservation and somatic cell nuclear transfer. Anim Reprod Sci 2007, 98:39-55.

2. Hinrichs K, Choi YH, Walckenaer BE, Varner DD, Hartman DL: In vitro-produced equine embryos: production of foals after transfer, assessement by differential staining and effect of medium calcium concentrations during culture. Theriogenology 2007, 68:521-529.

3. Stokes JE, Squires EL, Suh TK, Altermat JL, Carnevale EM: Effect of developmental stage of ICSI-produced equine embryos on pregnancy rates [abstract]. Reprod Fertil Dev 2009, 21:164.

4. Tremoleda JL, Stout TA, Lagutina I, Lazzari G, Bevers MM, Colenbrander B, Galli C: Effects of in vitro production on horse embryo morphology, cytoskeletal characteristics, and blastocyst capsule formation. Biol Reprod 2003, 69:1895-1906.

5. Rambags BP, Krijtenburg PJ, Drie HF, Lazzari G, Galli C, Pearson PL, Colenbrander B, Stout TA: Numerical chromosomal abnormalities in equine embryos produced in vivo and in vitro. Mol Reprod Dev 2005, 72:77-87.

6. Pomar FJ, Teerds KJ, Kidson A, Colenbrander B, Tharasanit T, Aguilar $B$, Roelen BA: Differences in the incidence of apoptosis between in vivo and in vitro produced blastocysts of farm animal species: a comparative study. Theriogenology 2005, 63:2254-2268.

7. Bustin SA, Benes V, Nolan T, Pfaffl MW: Quantitative real-time RT-PCR: a perspective. J Mol Endocrinol 2005, 34:597-60I.

8. Bustin SA, Nolan T: Pitfalls of quantitative real-time reversetranscription polymerase chain reaction. J Biomol Tech 2004, 15:155-166.

9. Kubista M, Andrade JM, Bengtsson M, Forootan A, Jonák J, Lind K, Sindelka R, Sjöback R, Sjögreen B, Strömbom L, Ståhlberg A, Zoric N: The real-time polymerase chain reaction. Mol Aspects Med 2006, 27:95-125.

10. Dheda K, Huggett JF, Chang JS, Kim LU, Bustin SA, Johnson MA, Rook GA, Zumla $A$ : The implications of using an inappropriate reference gene for real-time reverse transcription PCR data normalization. Anal Biochem 2005, 344:|4|-I43.

II. Vandesompele J, De Preter K, Pattyn F, Poppe B, Van Roy N, De Paepe A, Speleman F: Accurate normalization of real-time quantitative RT-PCR data by geometric averaging of multiple internal control genes. Genome Biol 2002, 3:0034.I-0034.I I.

12. Goossens K, Van Poucke M, Van Soom A, Vandesompele J, Van Zeveren A, Peelman LJ: Selection of reference genes for quantitative real-time PCR in bovine preimplantation embryos. $B M C$ Dev Biol 2005, 5:27.

13. Mamo S, Gal AB, Bodo S, Dinnyes A: Quantitative evaluation and selection of reference genes in mouse oocytes and embryos cultured in vivo and in vitro. BMC Dev Biol 2007, 7:14.

14. Kuijk EW, du Puy L, van Tol HT, Haagsman HP, Colenbrander B, Roelen BA: Validation of reference genes for quantitative RTPCR studies in porcine oocytes and preimplantation embryos. BMC Dev Biol 2007, 7:58.

15. Mamo S, Gal AB, Polgar Z, Dinnyes A: Expression profiles of the pluripotency marker gene POU5FI and validation of reference genes in rabbit oocytes and preimplantation stage embryos. BMC Mol Biol 2008, 9:67.

16. Rambags BP, van Tol HT, Eng MM van den, Colenbrander B, Stout TA: Expression of progesterone and oestrogen receptors by early intrauterine equine conceptuses. Theriogenology 2008, 69:366-375

17. Choi YH, Harding HD, Hartman DL, Obermiller AD, Kurosaka S, McLaughlin KJ, Hinrichs K: The uterine environment modulates trophectodermal POU5FI levels in equine blastocysts. Reproduction 2009, I38:589-599.

18. Bogaert L, Van Poucke M, De Baere C, Peelman L, Gasthuys F, Martens A: Selection of a set of reliable reference genes for quan- 
titative real-time PCR in normal equine skin and in equine sarcoids. BMC Biotechnol 2006, 6:24.

19. Cappelli K, Felicetti M, Capomaccio S, Spinsanti G, Silvestrelli M, Supplizi AV: Exercise induced stress in horses: selection of the most stable reference genes for quantitative RT-PCR normalization. BMC Mol Biol 2008, 9:49.

20. Tremoleda JL, Van Haeften T, Stout TA, Colenbrander B, Bevers MM: Cytoskeleton and chromatin reorganization in horse oocytes following intracytoplasmic sperm injection: patterns associated with normal and defective fertilization. Biol Reprod 2003, 69:186-194.

21. Dafforn A, Chen P, Deng G, Herrler M, Iglehart D, Koritala S, Lato S, Pillarisetty S, Purohit R, Wang M, Wang S, Kurn N: Linear mRNA amplification from as little as $\mathbf{5}$ ng total RNA for global gene expression analysis. Biotechniques 2004, 37:854-857.

22. Andersen CL, Jensen JL, Ørntoft TF: Normalization of real-time quantitative reverse transcription-PCR data: a model-based variance estimation approach to identify genes suited for normalization, applied to bladder and colon cancer data sets. Cancer Res 2004, I 64:5245-5250.

23. Pfaffl MW, Tichopad A, Prgomet C, Neuvians TP: Determination of stable housekeeping genes, differentially regulated target genes and sample integrity: BestKeeper--Excel-based tool using pair-wise correlations. Biotechnol Lett 2004, 26:509-5I5.

24. Willems E, Mateizel I, Kemp C, Cauffman G, Sermon K, Leyns L: Selection of reference genes in mouse embryos and in differentiating human and mouse ES cells. Int J Dev Biol 2006, 50:627-635.

Publish with Bio Med Central and every scientist can read your work free of charge

"BioMed Central will be the most significant development for disseminating the results of biomedical research in our lifetime. "

Sir Paul Nurse, Cancer Research UK

Your research papers will be:

- available free of charge to the entire biomedical community

- peer reviewed and published immediately upon acceptance

- cited in PubMed and archived on PubMed Central

- yours - you keep the copyright 